\title{
Research Directions Profile in the Computing Museum of the Institute of Mathematics and Computer Science, University of Latvia (IMCS)
}

\author{
Rihards Balodis, Juris Borzovs, Inara Opmane, \\ Andrejs Skuja, and Evija Ziemele \\ Institute of Mathematics and Computer Science, University of Latvia \\ Raina bulv.29, LV-1459, Riga, Latvia \\ \{Rihards Balodis, Juris Borzovs, Inara Opmane, Andrejs Skuja, \\ Evija Ziemele\}imcs@lumii.lv
}

\begin{abstract}
The article describes the development of information technology in Latvia, in IMCS, to the middle of the 1990s. The history of IMCS represents the usage of computers in typical computing centers in the former Soviet Union and the transformation from computing center to research institution. It also represents Latvian collaboration with the Nordic countries that provided political, scientific, and technological support. Historical documents, computer parts, and photos are collected in the Computer Museum of IMCS.
\end{abstract}

Keywords: Computing museum, history of computing technology, Latvia, research institute.

\section{Institute of Mathematics and Computer Science}

The Institute of Mathematics and Computer Science at the University of Latvia (IMCS) was established in 1959 as a computing research center. Although it was part of the University of Latvia, the government set it up and from the beginning, it always had its own budget. The funding of the Institute of Mathematics and Computer Science was through government research grants and contracts. It was the fourth computing research center in the Soviet Union, established with the goal of developing Latvian industry. Since the founding of the institute, the best computing machines available in the USSR were installed and used there. Over the years the use of computing technology and the relevant scientific technological field itself, had changed significantly.

The number of people employed at the institute varied over the years, ranging from 120 to 450 . Currently, 230 employees work at IMCS and it is the largest and most relevant research institution in Latvia in the fields of information technology, mathematics, computer science, and computer linguistics. In recent years, new scientific groups were established for the development of interdisciplinary research and e-infrastructures (e.g., GEANT, GRID, and cloud computing). 


\section{History of Computer Use in IMCS}

Over the years, computing machines in IMCS were replaced with more advanced and progressive units, along with the development of technology. Engineers wanted to keep up with rapidly changing technologies and collected more interesting computer parts. The Computing Museum, established in 1984, was founded by IMCS and actually also constitutes the history of IMCS. Since IMCS is currently the largest information technology research center in Latvia, to some extent it also constitutes the history of Latvian information technology. The documents and equipment in the museum reflect the computing machines of a passing age, their description, and the tasks solved with them.

Currently, the Computing Museum occupies $230 \mathrm{~m}^{2}$, holds 13,116 exhibits, of which 504 are equipment units, 287 mainframe and workstation parts, 98 computers, and 44 printers. The museum exhibits were complemented with photographs and documents that seemed to have historical value.

The museum has an exhibit for each computing machine used in IMCS. It is either in the form of a photograph, a separate computing unit or component, or as in several cases the complete machine. The history shows how in the transition from Soviet model computers (BESM and MINSK) to Western computers (e.g., IBM and PDP) cloning had taken place and how the regaining of Latvian independence changed the assessment values of technology. For example, efficiency started to play an important role and thus the operation of the service demanding ES EVM was prematurely suspended. The former engineer of IMCS with more than forty years of work experience, who describes the exhibits with illustrations from his own background, heads the museum.

\subsection{First Computers in IMCS}

The original computers became operational during the initial stages of the development of the information technology field in the USSR. The first, a BESM-2, went into commercial production in 1958. IMCS acquired the machine; it had production number " 5 " - a fact that serves as substantial evidence for the role and competence of the computing center. BESM-2 was a demanding machine that required a great amount of engineering work, but IMCS's engineers were innovative and could introduce several important upgrades that enabled the respective machine to be more efficient. In this regard, IMCS had one of the best results in the entire Soviet Union.

At the end of the 1960s, IMCS started using the Minsk series computers. The machine had a decimal (decimal-binary) notation with the point fixed after the lower bit; numbers and instructions were coded with a variable-length sequence of characters. In addition, the instruction set had a variable number of addresses for operands, and the instruction addresses were normalized and indexed.

The circuitry and instruction set of Minsk-23 completely differed from those computers that had existed before it. The machine was the first domestic computer with alphanumeric logic as well as a variable word and instruction length. A multitasking mode was also realized in Minsk-23. The Minsk-32 closed the Minsk computer series. 
Table 1. First computers used in IMCS

\begin{tabular}{ll}
\hline Usage years & Computer \\
\hline $11.04 .1961-21.08 .1970$ & BESM-2 (first generation, vacuum tubes, \\
& 5,000 op/s) \\
$29.06 .1964-03.04 .1972$ & BESM-2M \\
$11.04 .1967-06.04 .1978$ & BESM-4 (second generation, transistors, \\
& 20,000 op/s) \\
& Computer modernization with FACIT ECM \\
& 64 \\
$1968-1975$ & Minsk-22, Minsk-23, Minsk-32 $(7,000 \mathrm{op} / \mathrm{s})$ \\
\hline
\end{tabular}

In very special cases, IMCS bought Western computers, for example, IMCS had been granted funds to buy the GE415. This allowed IMCS scientists to compare the level of computer technology progress in the USSR and the West and to comprehend the tasks that were necessary for software development. GE415 was a second-generation computer with transistors that executed 40,000-90,000 op/s. GE400(s) computers were time-sharing information systems produced by General Electric, introduced in 1964 and exported until 1968. IMCS used the GE415 from 03.09.1969 until 03.04.1983.

\subsection{Mainframes in IMCS}

Soviet economic planners decided to use the IBM design, although some prominent Soviet computer scientists had criticized the idea and suggested that one of the Soviet indigenous designs such as BESM or Minsk should be chosen instead. The first work on the cloning began in 1968; production started in 1972. Thereafter, the first subseries of the ES EVM, released in 1969-1978, included models 1010, 1020, 1030, 1040, and 1050, which were analogous to System/360, and the more rare and advanced models 1022, 1032, 1033 and 1052, which were incompatible with the IBM versions. The electronics of the first models were based on TTL circuits; the later machines used the ECL (emitter-coupled logic) design. ES 1050 had a maximum of 1 MB RAM and 64-bit floating point registers. The fastest machine of the series, the ES 1052, was developed in 1978. (Note that data regarding computer models and their relevance to cloned models come from Wikipedia.)

The second subseries, released in 1977-1978, included the models 1015, 1025, 1035, 1045, 1055 and 1060, all analogous to the System/370.

Table 2. Mainframe types used in IMCS

\begin{tabular}{ll}
\hline Usage years & Computer types \\
\hline $16.05 .1974-31.12 .1978$ & ES EVM-1020 (3. generation, integrated \\
& circuits, 11,800 op/s) \\
$1976-31.12 .1987$ & ES EVM-1022 $(80,000 \mathrm{op} / \mathrm{s})$ \\
$02.1980-31.12 .1987$ & ES EVM-1022-02 $(80,000 \mathrm{op} / \mathrm{s})$ \\
$12.1982-1990$ & ES EVM-1060-02 $(100,000 \mathrm{op} / \mathrm{s})$ \\
$02.03 .1983-06.1989$ & ES EVM-1055M $(450,000 \mathrm{op} / \mathrm{s})$ \\
$25.10 .1989-10.1992$ & ES EVM $-1037 ”(4,000,000 \mathrm{op} / \mathrm{s})$ \\
\hline
\end{tabular}


After Latvia regained independence, the operation of ES EVM was suspended in 1992 due to the costs of service, electricity, and the numerous maintenance staff.

\subsection{Workstations in IMCS}

The SM-4 was a Soviet PDP-11/40 computer clone. SM EVM was a general name for several types of Soviet minicomputers. Production started in 1975. Most types of SM EVM are clones of the DEC PDP-11 and the VAX. The common operating system was MOS, a clone of UNIX. The IZOT was a Bulgarian produced model.

Table 3. Workstation types used in IMCS

\begin{tabular}{ll}
\hline Usage years & Computer types \\
\hline $23.03 .1981-06.1989$ & SM-4 $(180,000 \mathrm{op} / \mathrm{s})$ \\
$24.03 .1985-05.1989$ & IZOT-1016S \\
$30.04 .1987-1990$ & IZOT-1055S \\
$07.06 .1989-1990$ & IZOT-1080 $(4,500,000 \mathrm{op} / \mathrm{s})$ \\
\hline
\end{tabular}

\subsection{Microcomputers and Personal Computers in IMCS}

Acorn's BBC Micro computer dominated the UK educational computer market during the 1980s and early 1990s, drawing many comparisons with Apple in the US. The Wang 2200 was cloned by the Soviet Union and produced as "Iskra 226." DVK was a computer series of DEC PDC-11 and PDP-11, while the Elektronika BK was a series of 16-bit PDP-11-compatible Soviet home computers, almost perfectly compatible with the DEC LSI-11 line. These computers were used in schools for informatics classes: one KUVT and many BK or Yamaha, later AGAT (Apple-II). The KUVT was based on a Z80 CPU (in fact, an Eastern clone of Intel 880), and used SCP, a CP/M compatible operating system. It was widely used in Russia and other East European countries for office and educational purposes. Iskra 1030 was a Soviet 8086 compatible personal computer.

At the end of the 1980s and the beginning of the 1990s, the rapid transition to Western personal computers started.

Table 4. Microcomputers and personal computer types used in IMCS

\begin{tabular}{ll}
\hline Usage years & Computer types \\
\hline $1985-1993$ & Acorn UK education class \\
$1986-1993$ & Previous generation of personal computers: \\
& ISKRA-226 \\
& DVK \\
& KUVT-86 \\
& BK-0010 \\
& Robotron - 1715 (East Germany) \\
& Yamaha (JAPAN) \\
& ISKRA-1030, IBM XT, AT, Mazovia, PS2 \\
\hline
\end{tabular}




\section{Profile Components - Signs of Age}

What were the original tasks solved and how did the technology help? The following is a brief overview.

a. IMCS had a scientific spirit - there were many technological deficiencies in the first industrial Soviet computers that demanded refinements, which were carried out in IMCS by an innovative laboratory of engineers and electricians;

b. The installation of the first computers substantially contributed to the growth of research, particularly in the development of methods for the mathematical modeling of various physical processes, in the development of software, and research in theoretical computer science (Tables 5 and 6);

c. Along with the research, practical information systems for the Latvian economy were developed (Table 7);

d. From the 1970s onwards, cloning was a trend, but IMCS retained its initiative in carrying out original research. IMCS cloned only one system - CRJE (DUVZ), the adoption of Conversational Remote Job Entry (Clone of CRJE) for OS ES EVM (Clone of OS/360).

Mathematical scientists and highly qualified engineers worked in the institute. Owing to practical tasks - mainly solving specifically commissioned assignments with methods of mathematical modeling - the initiative emerged to develop such software that solved specific assignments and large groups of them. Thus the first IT research directions appeared. Original software was developed - compilers and software development tools (Table 6), for example, computer usage counting system, software development, and complex systems modeling languages and tools (later GRADE, MOLA), now - semantic WEB (term coined by W3C director Tim Berners-Lee).

Three activity directions of the institute were the result of specific assignments the development of information systems, mathematical models in natural sciences, and research in computer science. The history of IMCS illustrates how very limited computing resources contributed to the evolution of theoretical research fields.

Table 5. Research directions developed in IMCS

\begin{tabular}{|c|c|}
\hline Research direction & Description \\
\hline $\begin{array}{l}\text { Software debugging and } \\
\text { testing }\end{array}$ & $\begin{array}{l}\text { From the development of automation tools for } \\
\text { practical needs to theoretical research and } \\
\text { experimental systems }\end{array}$ \\
\hline $\begin{array}{l}\text { Inductive synthesis of } \\
\text { algorithms from examples }\end{array}$ & Theoretical research and experimentation \\
\hline Specification languages & $\begin{array}{l}\text { For telephone exchange, real time systems and } \\
\text { business models }\end{array}$ \\
\hline Software development tools & Research and development of tools \\
\hline $\begin{array}{l}\text { Modeling and simulation of } \\
\text { discrete processes }\end{array}$ & $\begin{array}{l}\text { Theory, practical simulation of telephone } \\
\text { exchange call load balancing }\end{array}$ \\
\hline Computational linguistics & Latvian language research with computers \\
\hline Graph theory & From theory to printed circuit board design \\
\hline $\begin{array}{l}\text { Mathematical methods and } \\
\text { modeling of physical } \\
\text { processes }\end{array}$ & Theory and computer modeling \\
\hline
\end{tabular}


Table 6. Notable original software developed in IMCS from 1970 to 1980

\begin{tabular}{|c|c|c|}
\hline $\begin{array}{l}\text { Programming language } \\
\text { or software tool }\end{array}$ & Description & $\begin{array}{l}\text { Computer } \\
\text { (operating system) }\end{array}$ \\
\hline Fortran & $\begin{array}{l}\text { Compiler implementation; compiler had } \\
\text { restrictions }\end{array}$ & BESM-4 \\
\hline SMOD & $\begin{array}{l}\text { Macro command system for information system } \\
\text { development }\end{array}$ & Minsk-32 \\
\hline TRANS & $\begin{array}{l}\text { Automation of translation, debugging and } \\
\text { execution of programs }\end{array}$ & Minsk-32 \\
\hline PL/I & $\begin{array}{l}\text { Original PL/I Compiler. Interpreter of PL/I } \\
\text { commands for software debugging in visual } \\
\text { PL/I machine. PL/I Handbook, printed twice in } \\
\text { Statistika (Moscov), Polish translation of book } \\
\text { (Warsaw) }\end{array}$ & $\begin{array}{l}\text { OS ES EVM } \\
\qquad(\text { Clone of OS/360) }\end{array}$ \\
\hline RIGAL & Language and tools for Compiler implementation & $\begin{array}{l}\text { OS ES EVM } \\
\text { (Clone of OS/360), } \\
\text { SM- } 4 \text {, IZOT }\end{array}$ \\
\hline $\begin{array}{l}\text { SDL (System } \\
\text { description } \\
\text { Language) }\end{array}$ & $\begin{array}{l}\text { Real System specification language: tools used for } \\
\text { system prototyping and debugging. }\end{array}$ & SM-4, IZOT \\
\hline $\begin{array}{l}\text { MAUS (Computer } \\
\text { usage account } \\
\text { system) }\end{array}$ & $\begin{array}{l}\text { System that counts usage of all computer } \\
\text { resources (processor, peripherals, I/O } \\
\text { operations) and calculates expenses. }\end{array}$ & $\begin{array}{l}\text { OS ES EVM (Clone of } \\
\text { OS/360), MAUS } \\
\text { included in the base of } \\
\text { the operating system and } \\
\text { maintained in all Soviet } \\
\text { produced computers }\end{array}$ \\
\hline
\end{tabular}

Table 7. Information systems developed in IMCS from 1970 to 1980

\begin{tabular}{|c|c|}
\hline Description & $\begin{array}{l}\text { Computer } \\
\text { (operating system) }\end{array}$ \\
\hline $\begin{array}{l}\text { Wholesale store for agriculture, including } \\
\text { accounting system }\end{array}$ & Minsk-22, Minsk-32 \\
\hline City traffic simulation system & BESM-4 \\
\hline $\begin{array}{l}\text { Operative planning system for production in } \\
\text { enterprise }\end{array}$ & GE-415 \\
\hline $\begin{array}{l}\text { Information system for electronics production at } \\
\text { Factory Komutators }\end{array}$ & Ge-415 \\
\hline Construction and building management system & $\mathrm{Ge}-415$ \\
\hline Higher education student registration system & OS ES EVM \\
\hline Agricultural resources optimization for land usage & OS ES EVM \\
\hline Pension calculation and payment system & OS ES EVM \\
\hline Informatics in schools & $\mathrm{PC}$ \\
\hline
\end{tabular}

\section{Collaboration with Nordic Countries}

Hereafter we illustrate the extensive cooperation with the Nordic countries that commenced in the 1990s.

Over the ages, the Baltic Sea has separated and united Latvia and the Scandinavian states. Only 500 kilometers separates Riga from Stockholm and there is only a distance of 200 kilometers between Ventspils and Visby. During the Soviet years, 
cooperation with the Nordic countries was uncommon; an exception was the modernization of BESM-4 with FACIT ECM 64 (ECM 64 is the magnetic tape storage unit or the Carousel Memory, developed by Facit Electronics AB, Stockholm).

After Latvia gained its independence, cooperation with the Nordic countries started and it brought political, scientific, and technological support. Three directions of cooperation follow.

\subsection{Collaboration with Oy International Business Machines AB, Tietokuja 2, Helsinki}

The first initiatives in IBM commencing its operation in Latvia began in the spring of 1991; however, a contract between IMCS and the IBM branch in Helsinki was signed in May of 1992. Within the framework of the contract, IBM and IMCS provided each other with mutual consultations. The IBM operation in Latvia was equally important to the development of IMCS and the development of the information technology field in Latvia in general, encouraging its dynamic growth with technology exhibitions, annual industry conferences, and other cooperative ventures.

\subsection{Collaboration with the Swedish Institute}

The Swedish Institute (SI) is a public agency that promotes interest and confidence in Sweden, around the world. After the Baltic States (Estonia, Latvia, Lithuania) regained their independence at the beginning of 1990, the Scandinavian countries helped considerably to establish relations between them and the Western academic community. The SI provided the possibility for Latvian information technology scientists to visit and work for a short period at KTH in Stockholm, Chalmers University of Technology in Gothenburg, as well as at Uppsala, Linköping, and other research centers. Two co-authors of this paper also enjoyed the hospitality of Professor Janis Bubenko, Jr. during their sabbatical leave at the Royal Institute of Technology in 1991. Through increased contacts and new networks, knowledge and innovative ideas could be shared and applied to many future research areas. Professor Janis Bubenko, Jr. (Royal Institute of Technology) and Professor Arne Sølvberg (Trondheim Technical University) jointly established the biannual international conference "Baltic Databases and Information Technology." The ninth DB\&IS has taken place in 2010. Both professors are still working on the Advisory Committee of DB\&IS.

Professor Janis Bubenko, Jr. has received the Honoris Causa Doctor award from Riga Technical University (2004) and the University of Latvia (2010).

\subsection{Collaboration with NORDUnet}

After the restoration of Latvian independence, IMCS began to work on building an IP network. In 1992, IMCS leased the Lattelekom and ESTI telekom analog communication channel to Tallinn. As of 1993, NORDUnet provided help in developing an IP network for research and educational purposes. Their help was useful both technologically and financially. Controversies over which network solution (X.25 or IP) was the most appropriate had lasted until 1995; Lattelekom with 
its technology supported X.25 and NORDUnet's actively defended introduction of the internet platform.

In 1995, LATNET (a network maintained by the Laboratory of IMCS) had a $64 \mathrm{k}$ link via Tallinn to Helsinki (FUNET) and a 128k link to Stockholm KTH (NORDUnet). Two links had implemented load sharing, so the aggregated capacity was $192 \mathrm{k}$ (which was at 100 percent capacity during the day). The five largest universities, about ten research institutions, three libraries, and many other non-profit organizations were connected to LATNET. Inside LATNET, new service providers were emerging such as LANET (another Latvian Academic Network) and Bank Communications Center. LATNET received almost no local assistance for the support of academic users; some sponsorship came from commercial users and a great deal from the Nordic Council of Ministers and PHARE (The Program of Community aid to the countries of Central and Eastern Europe), who were paying for international lines and donating equipment. Unfortunately, no one wanted to pay all the people who operated it; commercial users sponsored the small daily expenses, local lines, and dial-up pools.

The wireless internet access network in Latvia was started in 1993 when the IMCS (LATNET) installed the first citywide wireless LAN link to connect a remote university campus to the central building, a distance of five kilometers between them. At that time, spread spectrum wireless LAN technology was little known. The inspiration to start these tests came from a Cylink demonstration of spread spectrum link of wireless data at the INET'93 workshop in San Francisco, and from the staff at KTH network operations center in Stockholm who brought the first wireless LAN cards to Riga in the autumn of 1993.

The work [1] summarizes the Nordic countries' point of view on the cooperation with LATNET (at present Sigmanet), the laboratory of IMCS.

The first contacts with Baltic computer scientists were created when the NORDUNET program was still operational. Members of the NORDUnet community were active in this new collaboration. In Finland, Estonian scientists interested in building data networks contacted FUNET. In Sweden, the Latvians first approached the Swedish Institute for Computer Science (SICS). In Norway, Rolf Nordhagen, from the University of Oslo, cooperated with the Lithuanians. Rolf Nordhagen recalls that in fact the first outside network connection from a Baltic country was established from Vilnus, Lithuania, to the Norwegian Uninett via satellite already by 1991 .

Mats Brunell, the project manager of the NORDUnet program, was working at SICS when the Latvian Institute of Electronics and Computer Science contacted the Swedish to establish research collaboration. The Baltic researchers expressed their interest in getting a connection to NORDUnet and via NORDUnet also to the internet.

Brunell began to organize a project for Nordic-Baltic networking collaboration. After a visit to Riga, Latvia, in May of 1991, Brunell initiated the BALTnet project with the objective of establishing communication services with the Baltic States, primarily for the research and education community. The funding for the project was sought and received from the Nordic Council of Ministers; it granted 7.5 million Danish crowns for the BALTnet project.

The BALTnet project came into being in 1993 and Mats Brunell became its project leader. He continued in this task until 1995. Then the BALTnet project was moved from SICS to the University of Oslo and Rolf Nordhagen took over the management. 
The goal of BALTnet was to support the development of Baltic education and research networks. The work was accomplished by organizing seminars for Baltic networkers, buying equipment for research institutes and financially supporting international connectivity. In addition, the Nordic networking specialists helped Baltic scientists to establish contacts with other European networkers and with networkers in the United States.

Peter Villemoes considers that the NORDUnet community played a very important role in the Baltic countries when the three countries were building their first research networks. According to Villemoes, the early collaboration and connection to NORDUnet and to the Internet had a beneficial effect on Baltic networking collaboration with the Nordic countries ensured that "of the former Soviet states, the Baltic countries became the most advanced in networking."

The success of networking in Latvia and in all the Baltic States was based on international cooperation and help, including the support of the Nordic Council of Ministers. For example, LATNET (at present Sigmanet) was the Latvian partner in the BALTnet project established by the Nordic Council of Ministers in 1993.

\section{Reference}

1. Lehtisalo, K.: The History of NORDUnet: Twenty-Five Years of Networking Cooperation in the Nordic Countries,

http: //www.nordu.net/history/TheHistoryOfNordunet_simple.pdf 